\title{
PENYISIPAN WATERMARK MENGGUNAKAN METODE DISCRETE COSINE TRANSFORM PADA CITRA DIGITAL
}

\author{
Reza Agustina ${ }^{1}$, Rosa Andrie Asmara ${ }^{2}$ \\ ${ }^{1}$ Teknik Informatika, Teknologi Informasi, Politeknik Negeri Malang \\ ${ }^{1}$ rezaagustinaa@gmail.com, ${ }^{2}$ rosaandrie@gmail.com
}

\begin{abstract}
Abstrak
Citra digital merupakan format data yang paling banyak tersebar luas di internet. Hal ini memberikan kemudahan bagi beberapa orang yang ingin mengunduh dan menyebarluaskan citra tanpa seijin pemiliknya. Masalah penyalahgunaan citra ini semakin rumit ketika masyarakat kurang peduli terhadap hak cipta orang lain. Dengan adanya permasalahan tersebut, maka diperlukan sebuah metode untuk melindungi hak cipta dari citra digital. Penyisipan watermark dengan metode Discrete Cosine Transform dapat diterapkan untuk meningkatkan keamanan pada citra digital. Dipilihnya metode ini karena metode ini lebih kokoh terhadap manipulasi citra terutama kompresi. Penyisipan watermark dilakukan pada frekuensi tinggi dari koefisien DCT. Berdasarkan pengujian, citra terwatermark tahan terhadap manipulasi citra berupa kompresi hingga 50\%. Penambahan teks dan perubahan warna menghasilkan kualitas citra watermark yang baik, sedangkan pada penggantian background, penambahan filter, dan rotate dapat merusak watermark setelah proses ekstraksi.
\end{abstract}

Kata kunci : Citra Digital, Discrete cosine transform, Watermarking

\section{Pendahuluan}

Pada era teknologi yang semakin pesat saat ini, internet menjadi salah satu sumber informasi untuk sebagian besar masyarakat yang dapat memudahkan untuk saling bertukar informasi dan pengambilan data dalam format digital, baik berupa teks, citra, audio, dan video. Citra merupakan salah satu data yang paling banyak tersebar luas di internet. Kemudahan ini merupakan hal yang menguntungkan bagi masyarakat yang ingin menyebarkan dan menduplikasi citra digital tanpa ingin membayar royalti. Tetapi selain memberikan keuntungan, hal ini juga menimbulkan kerugian bagi pemilik citra apabila terjadi penyalahgunaan dari penyebaran dan duplikasi data dilakukan secara ilegal tanpa seijin pemiliknya.

Watermarking merupakan sebuah teknik penyisipan informasi yang menunjukkan hak kepemilikan. Teknik dalam watermark dapat diklasifikasikan dalam dua kategori, yaitu domain spasial dan domain transform. Pada domain spasial watermark disisipkan dengan memodifikasi langsung nilai bit dari citra asli, sedangkan pada domain transform watermark disisipkan setelah citra asli ditransformasikan ke dalam bentuk sinyal terlebih dahulu. Domain spasial mempunyai kelebihan lebih mudah dan cepat dalam pembuatannya, namun umumnya watermark kurang kokoh terhadap manipulasi citra. Menurut (Rinaldi Munir, 2008), watermark pada domain transform mempunyai kelebihan lebih kokoh terhadap manipulasi citra. Sampai saat ini penelitian tentang digital watermarking pada domain transformasi telah banyak digunakan.

Pada penelitian ini, akan dirancang aplikasi penyisipan watermark pada domain transform dengan menggunakan metode Discrete cosine transform (DCT). Dipilihnya metode ini karena metode ini lebih kokoh terhadap manipulasi citra terutama kompresi. Tranformasi DCT merupakan pendekatan transformasi matematika yang diimplementasikan pada informatika dengan tujuan untuk mentransformasi citra dari domain spasial ke domain transfom. Dengan metode ini, diharapkan mampu melindungi hak cipta citra apabila terjadi permasalahan mengenai duplikasi atau hal yang merugikan antara pemilik citra dengan pihak lain yang mengambil citra secara illegal.

\section{Digital Watermarking}

Digital watermarking merupakan cabang ilmu dari steganography, yaitu teknik untuk menyembunyikan suatu informasi ke dalam sebuah media digital dengan tujuan untuk memberikan perlindungan. (Rinaldi Munir, 2004). Informasi yang disisipkan pada digital watermarking dapat berupa teks, citra, dan audio.

Ada beberapa kriteria dari watermark yang baik, yaitu:

- Imperceptibility : Watermark yang baik tidak terlihat dari penghilatan manusia/kasat mata. 
- Robustness : watermark harus tahan terhadap manipulasi file penampung, seperti kompresi file, scanning.

- Security : watermark hanya bisa dideteksi oleh pemilik data atau pihak yang berwenang.

- Recovery : data yang disisipkan harus dapat diambil kembali. Karena tujuan utama dari watermarking adalah perlindungan hak cipta. Jadi jika pada sewaktu-waktu terjadi hal yang merugikan, watermark dapat digunakan untuk autentikasi kepemilikan citra.

\section{Discrete cosine transform}

Penggunaan DCT pada pengolahan citra dilakukan dengan membagi citra ke dalam sub blok berukuran standar $8 \times 8$ piksel. Dimana sub blok $8 \times 8$ piksel tersebut akan menghasilkan 64 koefisien yang terdiri dari 1 koefisien DC (zero frequencies) yang terletak pada pojok kiri atas dan 63 koefisien AC yang terdiri dari 3 frekuensi, yaitu frekuensi rendah, frekuensi menengah, dan frekuensi tinggi. Pada Gambar 1 memperlihatkan pembagian frekuensi pada DCT.

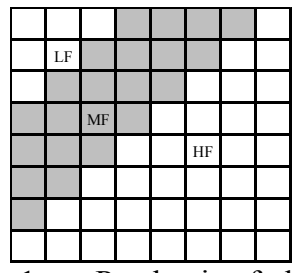

Gambar 1. Pembagian frekuensi DCT

LF digunakan untuk menyatakan komponen frekuensi terendah dari blok, sementara MF adalah frekuensi menengah, dan HF menyatakan komponen tertinggi dari blok. Rumus transformasi DCT dua dimensi adalah sebagai berikut:

$$
\begin{aligned}
F(u, v) & =\frac{4 C(u) C(v)}{N^{2}} \sum_{j=0}^{N-1} \sum_{k=0}^{N-1} f(j, k) \cos \left[\frac{(2 j+1) u \pi}{2 N}\right] \cos \left[\frac{(2 k+1) v \pi}{2 N}\right] \\
f(j, k) & =\sum_{j=0}^{N-1} \sum_{k=0}^{N-1} C(u) C(v) F(u, v) \cos \left[\frac{(2 j+1) u \pi}{2 N}\right] \cos \left[\frac{(2 k+1) v \pi}{2 N}\right]
\end{aligned}
$$

Dimana,

$$
\begin{aligned}
& C(w)=\frac{1}{\sqrt{2}}, \text { jika } w=0 \\
& C(w)=1, \text { jika } w>0 \quad N-1
\end{aligned}
$$

$f(j, k)$ adalah elemen $\mathrm{j}, \mathrm{k}$ dari citra yang direpresentasikan oleh matriks $f$. $N$ adalah ukuran dari sub blok DCT.

\section{Peak Signal to Noise Ratio}

Peak Signal to Noise Ratio (PSNR) merupakan pembanding yang digunakan untuk membandingkan nilai host image dengan nilai citra yang telah direkonstruksi. Semakin tinggi nilai PSNR, maka semakin baik juga tingkat kemiripan antara host image dengan citra yang telah dimanipulasi. Untuk menghitung nilai PSNR, sebelumya harus menghitung nilai Mean Square Error (MSE) dari kedua citra. MSE adalah nilai error kuadrat rata-rata antara host image dengan citra yang sudah direkonstruksi. Berikut merupakan rumus untuk perhitungan PSNR:

$$
\begin{gathered}
M S E=\frac{1}{M N} \sum_{i=1}^{M} \sum_{j=1}^{N}\left(f_{a}(i, j)^{2}-f_{b}(i, j)^{2}\right) \\
P S N R=10 \log _{10} \frac{M A X i^{2}}{M S E}
\end{gathered}
$$

Untuk image watermarking, kualitas citra terwatermark yang baik memiliki nilai PSNR $40 \mathrm{~dB}$ atau lebih (Cheddad, 2010).

\section{Proses Penyisipan Watermark}

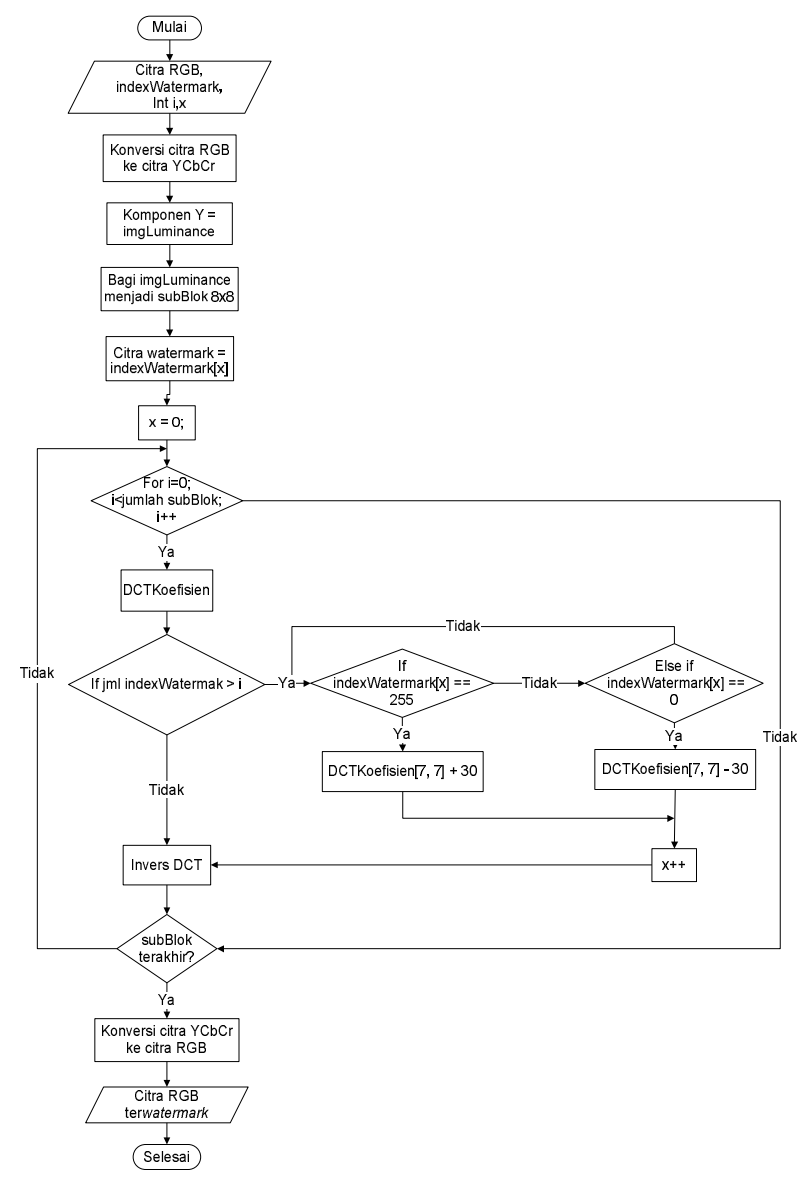

Gambar 2. Flowchart Penyispian Watermark

- User menginputkan host image, yaitu berupa citra RGB yang nantinya akan disisipi watermark. Sedangkan watermark disini tidak perlu diinputkan karena bersifat default.

- Selanjutnya citra RGB akan dikonversikan menjadi citra YCbCr, kemudian diambil komponen luminance (Y) saja untuk proses 
transformasi DCT. Hal ini karena sistem penglihatan manusia lebih sensitif terhadap intensitas cahaya. Dengan demikian diharapkan hasil imperceptible citra terwatermark lebih baik. Sedangkan komponen chrominance blue $(\mathrm{Cb})$ dan chrominance red $(\mathrm{Cr})$ tidak ditransformasikan dan digunakan pada saat proses invers DCT.

- Kemudian bagi komponen Y menjadi sub blok berukuran $8 \times 8$ piksel.

- Selanjutnya dilakukan transformasi DCT pada setiap sub blok. Untuk proses penyisipan, citra watermark adalah citra biner dengan nilai piksel 255 (putih) dan 0 (hitam). Jika piksel dari citra watermark bernilai 255 maka indeks ke [7, 7] dari koefisien DCT ditambah 30, sedangkan jika citra watermark bernilai 0 maka koefisien DCT dikurangi 30. Proses ini diulang sampai indeks watermark yang terakhir. Setelah mencapai indeks watermark yang terakhir maka dilakukan proses invers DCT untuk mendapatkan komponen Y terwatermark.

- Kemudian komponen Y digabungkan kembali dengan komponen $\mathrm{Cb}$ dan $\mathrm{Cr}$ sehingga membentuk citra YCbCr terwatermark.

- Proses terakhir konversikan kembali citra $\mathrm{YCbCr}$ terwatermark menjadi citra RGB sehingga menjadi citra RGB terwatermark.

\section{Tampilan Antarmuka}

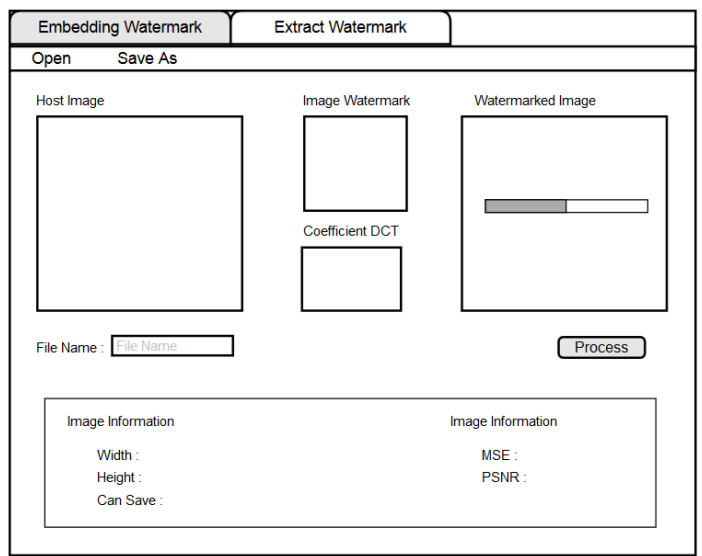

\section{Gambar 3. Tampilan borang embedding watermark}

\section{Hasil Pengujian}

Citra yang digunakan sebagai host image pengujian kali ini ditunjukkan pada Gambar

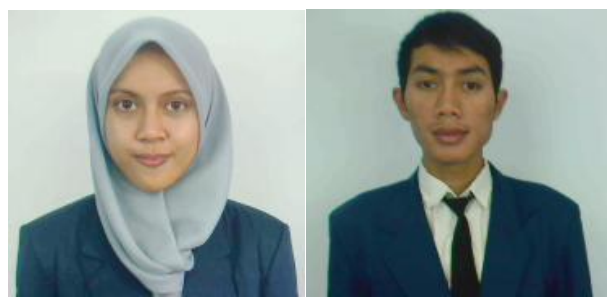

(a)

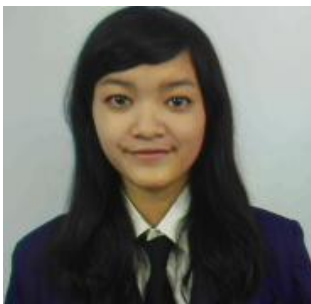

(c) (b)

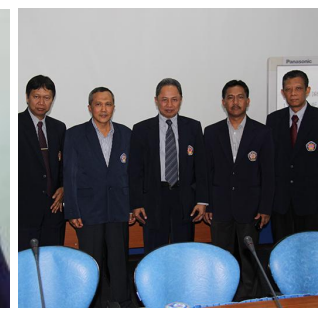

(d)
Gambar 4. (a) mhs1.jpg (b) mhs2.jpg (c) mhs3.jpg (d) direktur.jpg

Pengujian pertama adalah pengujian dari ukuran citra watermark yang akan disisipkan, tujuan dari pengujian ini adalah bagaimana pemilihan citra watermark yang baik untuk proses penyisipan pada host image dengan cara membandingkan dimensi ukuran dari citra watermark dan mengukur PSNR dari citra terwatermark. Hasil pengujian ini ditunjukkan pada Tabel 1.

Tabel 1. Hasil pengujian citra watermark

\begin{tabular}{|c|c|c|c|}
\hline $\begin{array}{c}\text { Dimensi } \\
\text { Watermark }\end{array}$ & Citra & MSE & PSNR \\
\hline \multirow{4}{*}{$40 \times 40$} & mhs1.jpg & 15.994 & 33.091 \\
\hline & mhs2.jpg & 15.999 & 36.089 \\
\hline & mhs3.jpg & 15.995 & 36.091 \\
\hline & direktur.jpg & 19.985 & 35.123 \\
\hline \multirow{4}{*}{$\begin{array}{l}\text { (1) } \\
32 \times 32\end{array}$} & mhs1.jpg & 15.992 & 36.091 \\
\hline & mhs2.jpg & 15.999 & 36.089 \\
\hline & mhs3.jpg & 15.996 & 36.091 \\
\hline & direktur.jpg & 8.138 & 39.026 \\
\hline \multirow{4}{*}{$\begin{array}{c}20 \times 20 \\
=2937\end{array}$} & mhs1.jpg & 12.789 & 37.062 \\
\hline & mhs2.jpg & 12.819 & 37.051 \\
\hline & mhs3.jpg & 12.848 & 37.042 \\
\hline & direktur.jpg & 2.0991 & 44.910 \\
\hline
\end{tabular}

Selanjutnya ditunjukkan hasil pengujian penyisipan watermark pada masing-masing frekuensi pada koefisien DCT pada Tabel 2.

Tabel 2. Hasil perbandingan antar frekuensi

\begin{tabular}{|c|c|c|c|}
\hline Frekuensi & Citra & MSE & PSNR \\
\hline \multirow{4}{*}{$\begin{array}{c}\text { Frekuensi } \\
\text { Rendah }\end{array}$} & mhs1.jpg & 28.429 & 33.593 \\
\cline { 2 - 4 } & mhs2.jpg & 28.446 & 33.591 \\
\cline { 2 - 4 } & mhs3.jpg & 28.584 & 33.569 \\
\cline { 2 - 4 } & direktur.jpg & 4.089 & 42.014 \\
\hline
\end{tabular}


Volume 2, Edisi 1, November 2015

\begin{tabular}{|c|c|c|c|}
\hline \multirow{4}{*}{$\begin{array}{c}\text { Frekuensi } \\
\text { Tengah }\end{array}$} & mhs1.jpg & 28.559 & 33.573 \\
\cline { 2 - 4 } & mhs2.jpg & 28.594 & 33.568 \\
\cline { 2 - 4 } & mhs3.jpg & 28.589 & 33.568 \\
\cline { 2 - 4 } & direktur.jpg & 4.102 & 42.001 \\
\hline \multirow{4}{*}{$\begin{array}{c}\text { Frekuensi } \\
\text { Tinggi }\end{array}$} & mhs1.jpg & 28.048 & 33.651 \\
\cline { 2 - 4 } & mhs2.jpg & 28.041 & 33.652 \\
\cline { 2 - 4 } & mhs3.jpg & 28.061 & 33.649 \\
\cline { 2 - 4 } & direktur.jpg & 4.033 & 42.075 \\
\hline
\end{tabular}

Pengujian selanjutnya dilakukan pengujian pada proses penyisipan citra watermark. Pada proses ini dilihat berapa piksel dari citra watermark yang dapat disisipkan ke dalam 1 sub blok koefisien DCT pada host image. Hasil pengujian ditunjukkan pada Tabel 3.

Tabel 3. Hasil penyisipan citra watermark

\begin{tabular}{|c|c|c|c|}
\hline $\begin{array}{c}\text { Banyak } \\
\text { Piksel }\end{array}$ & Host image & MSE & PSNR \\
\hline \multirow{4}{*}{1} & mhs1.jpg & 15.992 & 36.091 \\
\hline & mhs2.jpg & 15.999 & 36.089 \\
\hline & mhs3.jpg & 15.996 & 36.091 \\
\hline & direktur.jpg & 8.138 & 39.026 \\
\hline \multirow{4}{*}{2} & mhs1.jpg & 28.048 & 33.652 \\
\hline & mhs2.jpg & 28.041 & 33.652 \\
\hline & mhs3.jpg & 28.061 & 33.649 \\
\hline & direktur.jpg & 4.032 & 42.074 \\
\hline \multirow{4}{*}{4} & mhs1.jpg & 28.519 & 33.579 \\
\hline & mhs2.jpg & 28.548 & 33.574 \\
\hline & mhs3.jpg & 32.003 & 33.078 \\
\hline & direktur.jpg & 4.029 & 42.078 \\
\hline \multirow{4}{*}{8} & mhs1.jpg & 127.692 & 27.069 \\
\hline & mhs2.jpg & 33.457 & 32.886 \\
\hline & mhs3.jpg & 55.543 & 30.684 \\
\hline & direktur.jpg & 4.064 & 42.040 \\
\hline
\end{tabular}

Pengujian yang terakhir merupakan pengujian ketahanan citra terwatermark terhadap manipulasi citra. Hasil pengujian ditampilkan pada Tabel 4.
Tabel 4. Ketahanan citra terwatermark

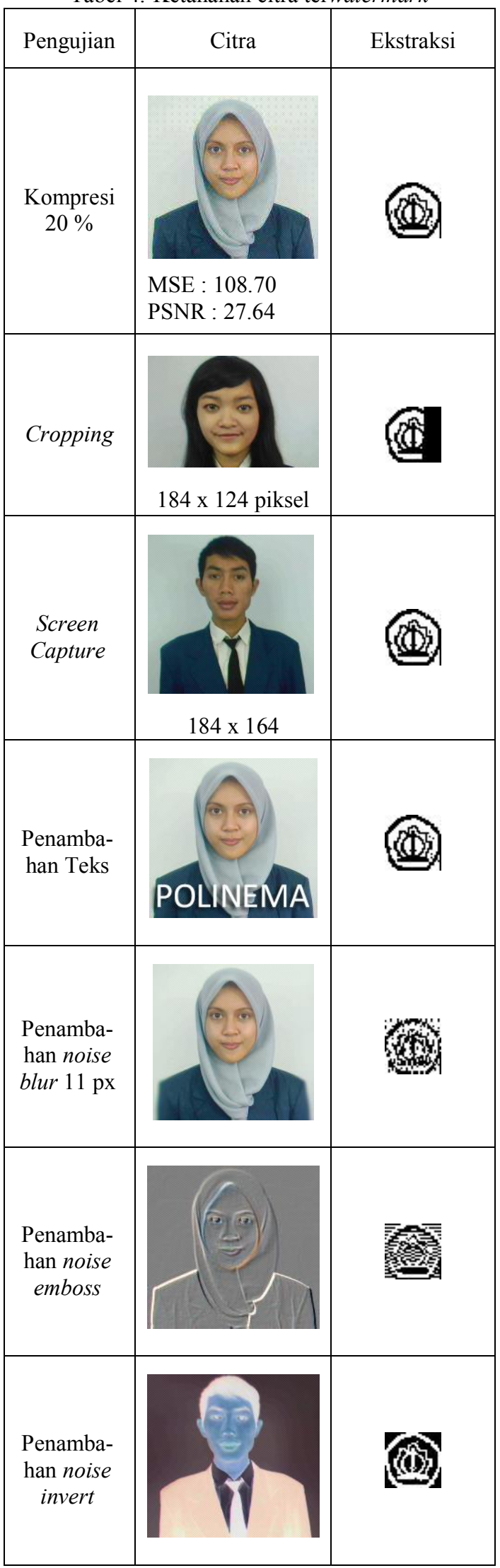




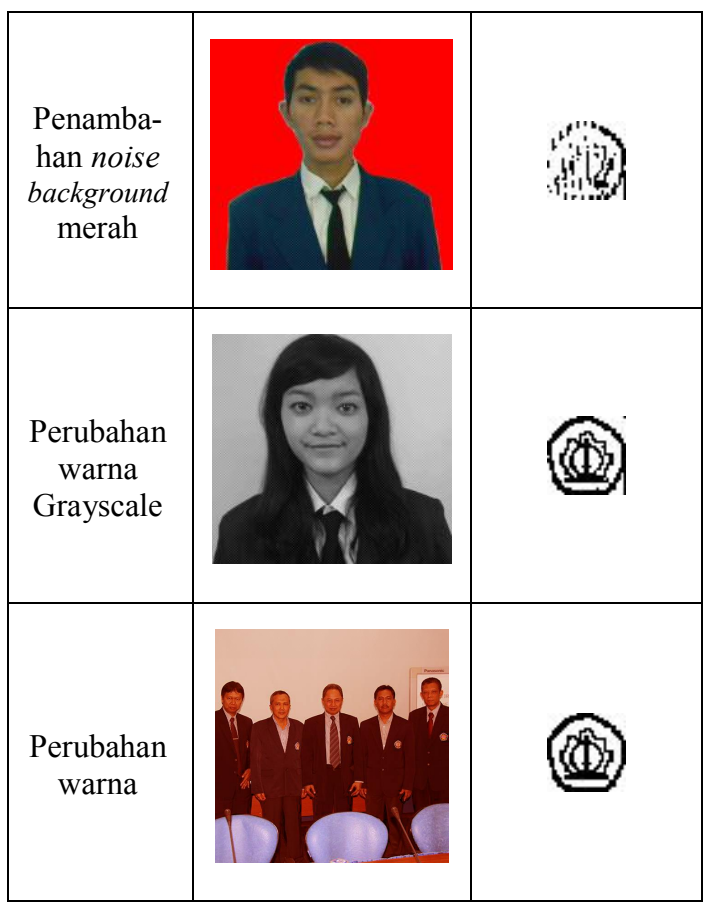

\section{Kesimpulan}

Penyisipan watermark menggunakan metode Discrete Cosine Transform telah dilakukan dengan menggunakan bahasa pemrograman Visual C\# .NET. Berdasarkan hasil pengujian yang telah dilakukan, dapat ditarik kesimpulan:

1. Penyisipan watermark menggunakan metode Discrete Cosine Transform dapat melindungi hak cipta pada citra digital.

2. Aplikasi penyisipan watermarking menggunakan metode Discrete Cosine Transform tidak dapat dikenali secara kasat mata.

3. Proses ekstraksi pada aplikasi penyisipan tidak membutuhkan citra asli.

4. Untuk mendapatkan hasil ekstraksi yang baik, perbandingan ukuran citra watermark dengan citra asli adalah 1:32 piksel.

5. Pengujian kompresi JPEG pada citra terwatermark menghasilkan citra terwatermark dapat tahan terhadap kompresi hingga $50 \%$ dan menghasilkan nilai PSNR yang cukup tinggi, yaitu $30 \mathrm{~dB}$.

6. Pengujian berupa screen capture menghasilkan citra watermark dengan kualitas yang rendah dengan nilai PSNR ratarata $25 \mathrm{~dB}$.

7. Pada pengujian citra berupa cropping, citra watermark akan hilang pada bagian yang terkena cropping.

8. Pengujian berupa perubahan warna dan penambahan teks menghasilkan hasil ekstraksi citra watermark dengan kualitas yang baik secara imperceptilibity, namun citra watermark memiliki nilai PSNR yang rendah karena bernilai di bawah $30 \mathrm{~dB}$, namun pada penggantian background dan penambahan filter berupa emboss dan penambahan filter blur menghasilkan ekstraksi citra watermark yang buruk, karena nilai PSNR yang sangat rendah atau bernilai di bawah $15 \mathrm{~dB}$.

\section{Saran}

Berdasarkan penelitian yang diperoleh, ada beberapa saran untuk pengembangan sistem lebih lanjut, sebagai berikut:

- Pada penelitian ini, manipulasi citra berupa kompresi di atas $50 \%$ dapat membuat watermark hilang. Untuk pengembangan selanjutnya diharapkan penambahan metode agar watermark lebih tahan terhadap manipulasi kompresi.

- Pada penelitian ini, watermark disisipkan dari sub blok pertama. Untuk penelitian selanjutnya diharapkan watermark dapat disisipkan secara acak agar lebih tahan terhadap manipulasi cropping dan rotate.

\section{Daftar Pustaka}

Amrullah, N, A. 2008. Perbandingan Algoritma LSB dan DCT Pada Steganografi

Anju, Reena and Vandana. 2013. "Modified Algorithm for Digital Image Watermarking Using Combined DCT and DWT". International Journal of Information and Computation Technology. 3(7), 693-694

Britanak, Vladimir., et all. Discrete Cosine and Sine Transforms. Academic Press

De Rosal, I. M. S., et all. 2012, "Robust Color Image Watermarking Dengan Kombinasi Transformasi DCT-DWT Untuk Meningkatkan Ketahanan Dari Kompresi JPEG”, Seminar Nasional Teknologi Informasi \& Komunikasi Terapan 2012

Hakim, A, R. 2012. Analisa Perbandingan Watermarking Image Menggunakan Discrete Wavelet Transform

Jaiswal, S dan Saxena, A. 2014. "A Review on Various Watermarking \& Information Hiding Techniuqes". International Journal of Emerging Technology and Advanced Engineering. 4(9)

Munir, Rinaldi. 2004. Steganografi dan Watermarking. Bandung: Departemen Teknik Informatika Institut Teknologi Bandung . 2010. "Image Watermarking untuk Citra Berwarna dengan Metode Berbasis Korelasi dalam Ranah DCT”. Jurnal Petir Vol.3 No. 1

Pravin M. Pithiya. 2013. "DCT Based Digital Image Watermarking, De- watermarking \& Authentication". 2(3)

Sangadji, I, B, M dan Rezeki, R,. 2009. "Pengukuran Kualitas Citra Ter-watermarking Model DCT 
Volume 2, Edisi 1, November 2015

(Discrete cosine transform) Menggunakan PSNR". Jurnal Petir. 2(1)

Singh, Vipula. 2011. "Digital Watermarking: A Tutorial”. Cyber Journals: Multidisciplinary Journals in Science and Technology, Journal of Selected Areas in Telecommunications (JSAT)

Singla, D dan Syal, R. 2012. "Data Security Using LSB \& DCT Steganography In Images". International Journal of Computational Engineering Research. Volume 2

Soleh, Muhamad. 2010. Analisis Dan Implementasi Watermarking Dengan Algoritma Aes Untuk Pemberian Data Hak Cipta Pada File Audio 